\title{
Cardiovascular Risk in Psoriasis Patients: Clinical, Functional and Morphological Parameters
}

\author{
Angélica Navarro de Oliveira, ${ }^{\circledR}$ Marcela M. Simões, Ricardo Simões, Marcus Vinicius Bolivar Malachias, ${ }^{(0)}$ \\ Bruno Almeida Rezende ${ }^{0}$ \\ Faculdade de Ciências Medicas de Minas Gerais - Instituto de Pós-Graduação, Belo Horizonte, MG - Brazil
}

\begin{abstract}
Background: Psoriasis correlates with metabolic disorders, early atheromatosis and increased cardiovascular risk.

Objectives: To assess markers of cardiovascular disease in psoriatic patients.

Methods: Cross-sectional, observational study involving 11 psoriatic participants and 33 controls. Anthropometric, biochemical, hemodynamic and imaging parameters were evaluated. Arterial stiffness was assessed by oscillometric measurement of the brachial artery. Intima-media thickness (IMT) and left ventricular diastolic function were assessed by Doppler echography and echocardiography. Between-group comparisons of numerical variables were performed by the Student's t-test or Wilcoxon Mann-Whitney test for independent samples. Significance level was set at $5 \%$.
\end{abstract}

Results: Psoriatic patients showed increased pulse wave velocity (PWV) $(9.1 \pm 1.8 \mathrm{vs} 8.0 \pm 2 \mathrm{~m} / \mathrm{s}, \mathrm{p}=0.033)$, IMT of the left common carotid artery $(p=0.018)$ and a higher percentage of patients above the $75^{\text {th }}$ percentile according to the ELSA table when compared with controls $(54.5$ vs $18.2 \%, p=0.045)$. Psoriatic patients also showed an increase in peripheral/ central systolic blood pressure $(137.1 \pm 13.2 \mathrm{vs} 122.3 \pm 11.6 \mathrm{mmHg}, \mathrm{p}=0.004) /(127 \pm 13 \mathrm{vs} 112.5 \pm 10.4 \mathrm{mmHg}$, $p=0.005)$, peripheral/central diastolic blood pressure $(89.9 \pm 8.9$ vs $82.2 \pm 8, p=0.022) /(91 \pm 9.3$ vs $82.2 \pm 8.3$, $\mathrm{p}=0.014)$, total cholesterol $(252 \pm 43.5 \mathrm{vs} 198 \pm 39.8 \mathrm{mg} / \mathrm{dL}, \mathrm{p}<0.001)$, LDL cholesterol $(167 \pm 24 \mathrm{vs} 118 \pm 40.8 \mathrm{mg} / \mathrm{dL}$, p $<0.001)$ and C-reactive protein $(7.6 \pm 35.4$ vs $1 \pm 1.2 \mathrm{mg} / \mathrm{L} \mathrm{p}<0.001)$ compared with controls.

Conclusion: Psoriasis patients show increased PWV, IMT, peripheral and central blood pressures, and serum cholesterol and C-reactive protein levels, denoting a higher cardiovascular risk. (Arq Bras Cardiol. 2019; 113(2):242-249)

Keywords: Cardiovascular Diseases; Psoriasis; Arterial Stiffness; Hypertension; Hypercholesterolemia; Oscillometry/ mehods; Brachial Artery.

\section{Introduction}

Psoriasis is an immune-mediated, recurrent chronic inflammatory disease of the skin and joints, affecting 2-4\% of the adult population in the world. ${ }^{1,2}$ Vulgar psoriasis is the most common type and occurs in $85-90 \%$ of psoriasis patients. It is phenotypically characterized by dry, red, scaly, silvery-white, well-defined plaques that appear mainly on elbows, knees, scalp, and the lumbar area. ${ }^{3}$ The cause of psoriasis is multifactorial, with numerous key components including genetic susceptibility, environmental triggers in combination with skin barrier disruption and immune dysfunction. ${ }^{3,4}$

Similarly to other autoimmune diseases, psoriasis is associated with well-documented systemic changes, including joint, endocrine, and cardiovascular dysfunctions..$^{5-8}$

Mailing Address: Angélica Navarro Navarro de Oliveira •

Faculdade de Ciências Medicas de Minas Gerais - Instituto de Pós-

Graduação - Alameda Ezequiel Dias, 275. Postal Code 30130-110, Belo

Horizonte, MG - Brazil

Email: angelicanavarro@terra.com.br

Manuscript received June 17, 2018, revised manuscript October 27, 2018, accepted November 21, 2018

DOI: $10.5935 / a b c .20190123$
Atherosclerosis is considered a chronic inflammatory disease of blood vessels and one of the most common mechanisms involved in the development of cardiovascular diseases (CVDs). The incidence of atherosclerosis is increased in psoriatic patients and seems to be directly associated with the severity of skin manifestations in these patients. ${ }^{6}$ In addition, previous epidemiological studies have shown the high prevalence of cardiovascular risk factors in psoriatics, including metabolic syndrome, obesity, hypertension, diabetes mellitus, insulin resistance and dyslipidemia. ${ }^{6,7,9-11}$

CVDs are the main cause of mortality in Brazil and in the world. For this reason, it is important to identify and correct their risk factors. ${ }^{12-14}$ There are several clinical and subclinical markers for early detection of cardiovascular risk, including physical examination findings, and metabolic, functional and imaging tests. ${ }^{15}$

Considering the close relationship between psoriasis and cardiovascular events, this study aimed to investigate subclinical cardiovascular change, measured by arterial stiffness (AS), common carotid artery intima-media thickness (IMT), and left ventricle diastolic dysfunction (LVDD), in addition to clinical and laboratory parameters in patients with moderate-to-severe psoriasis. The detection of these changes would contribute to early preventive and therapeutic measures. 


\section{Methods}

\section{Type of study}

This was a cross-sectional, analytical, observational study conducted between May 2016 and March 2018.

\section{Participants}

Psoriasis group (PG) was composed of 11 male volunteers, without evidence of CVD, aged between 40 and 65 years, with Psoriasis Area and Severity Index (PASI) $>7 .{ }^{16}$ All patients were consecutively included during their medical visit at a public health care center in Belo Horizonte, Brazil. All patients were classified as PASI $>10$, indicating severe skin manifestations of the disease. For the control group (CG), we selected 33 healthy men, without evidence of CVD or psoriasis, matched by age, recruited from the same health care center and from a private clinic in the same city. For the CG, patients seen for dermatological assessment due to conditions other than psoriasis. The number of subjects recruited was obtained by specific sample calculation proposed by Siqueira et al. ${ }^{17}$ Sample size was calculated assuming that variations in AS between PG and CG were similar. We also considered a proportion of three controls to one case, due to the low prevalence of severe psoriasis.

Exclusion criteria for both groups were: chronic diseases requiring nonsteroidal anti-inflammatory drugs (NSAIDs) or systemic corticosteroids, treatment for neoplasms or diagnosis of neoplasms less than five years, severe chronic kidney failure (glomerular filtration rate $<30 \mathrm{~mL} / \mathrm{min}$ ), liver failure or previous coronary diseases, peripheral vascular disease and $\mathrm{HF}$ with reduced ejection fraction. We also excluded from the study psoriasis patients with PASI $<7$.

All patients were seen by a cardiologist and assessed for smoking habit (smokers were considered those patients who smoked at least one cigarette per day in the last 12 months), ${ }^{18}$ alcohol consumption (15 doses/week in the last 12 months 1 dose corresponded to one can of beer), ${ }^{19}$ systemic arterial hypertension (according to the 2017 Brazilian Guidelines on Dyslipidemias and Prevention of Atherosclerosis), ${ }_{1}^{12}$ diabetes mellitus (according to the 2018 American Diabetes Association guidelines) ${ }^{20}$ use of medications, and any other factor that may be related to the exclusion criteria of the study.

All volunteers had their body weight and height measured for body mass index (BMI) calculation, body surface area (BSA) measured, and waist and hip circumferences measured for waist-to-hip ratio (WHR) calculation. These measurements were obtained using calibrated and certified (by INMETRO/ ANVISA) equipment.

Blood samples were collected for laboratory tests and measurement of C-reactive protein (CRP), LDL cholesterol, HDL cholesterol, and total cholesterol (TC).

Patients of the PG were classified according to the PASI, developed by Fredriksson and Pettersson in 1978 to assess the extent of the psoriatic plaques. ${ }^{21}$ This is the method of choice for the classification of the disease severity, ${ }^{16}$ and was applied by a dermatologist. Analysis of the severity and extent of the disease was made in four anatomical regions: head, trunk and upper and lower limbs.
Measurements of blood pressure (both peripheral/arm and central) and AS were obtained non-invasively using the monitor Mobil-O-Graph NG (IEM, Stolberg, Germany), with ARC Solver algorithm (the ARC Solver method, Austrian Institute of Technology). This is an oscillometric, 24-hour ambulatory blood pressure monitoring device, approved by the USA Food and Drug Administration and the Conformité Européenne. The method was validated according to the British Hypertension Society and recently by the American Heart Association's Council on Hypertension. ${ }^{22-24}$ After the measurement of the arm circumference and selection of the arm cuff, the device was positioned as proposed by the Brazilian Society of Cardiology. ${ }^{12}$ Three consecutive readings were taken automatically and the results were expressed as the mean of these three measurements. AS was estimated using the variables pulse wave velocity (PWV) and augmentation index (Alx) adjusted for a heart rate (HR) of 75 beats per minute (Alx@75). The monitor also provided the measurements of HR, systolic blood pressure (SBP), diastolic blood pressure (DBP) and peripheral and central pulse pressure (PP).

The analysis of IMT was performed by duplex scanning of the carotid arteries using the two-dimensional mode, and linear probe 10-MHZ Vivid S6 (GE healthcare, Telaviv, Israel), according to the recommendations of the Department of Cardiovascular Imaging of the Brazilian Society of Cardiology. ${ }^{25}$ The measurement of IMT was semi-automatically obtained one centimeter from the posterior wall of the common carotid artery. To determine the IMT percentile, the mean IMT (without including the plaque) of each segment was compared with those of the reference tables. The highest percentile for age of each participant was obtained. We used the tables obtained from the Brazilian Longitudinal Study of Adult Health (ELSA-Brasil), ${ }^{26}$ that evaluates chronic diseases in the Brazilian population aged from 40 to 65 years, of white, mulatto and black ethnicity, and from the Multi Ethnic Study of Atherosclerosis (MESA). ${ }^{27}$ Measures above the $75^{\text {th }}$ percentile were considered as significant increases.

A two-dimensional echocardiography with Doppler and tissue Doppler was performed following the American Society of Echocardiography (ASE) recommendations. ${ }^{28}$ We analyzed the electrocardiographic images of three cardiac cycles for the dimensions of the left ventricle, left atrial volume (LAV), parietal thickness, left ventricular mass index, left ventricular ejection fraction and color Doppler images of all valves. Analysis of the left ventricular diastolic function (LVDF) was performed according to the 2016 recommendations of the American Society of Echocardiography and the European Association of Cardiovascular Imaging. ${ }^{29}$ The following parameters were obtained: early left ventricular filling (E-wave), peak atrial filling wave (A-wave), E/A ratio, E-wave deceleration time, and isovolumic relaxation time. Tissue Doppler velocity measurements were obtained in the medial and in the lateral mitral annulus, in the four-chamber view, for the measurement of the peak early diastolic velocity (e'). The 2016, ${ }^{29}$ American Society of Echocardiography recommendations were also used for classification of diastolic function - normal function, diastolic dysfunction grade II (pseudonormal pattern), and diastolic dysfunction grade III (restrictive pattern). Subclinical dysfunction (i.e., asymptomatic condition) was diagnosed by left ventricular systolic and/or diastolic dysfunction. 
The echocardiographist could not be blinded to psoriasis, since skin manifestations of the disease are clinically evident.

\section{Statistical analysis}

Categorical variables were expressed as counts and percentages. Numerical variables were tested for normality by the Shapiro-Wilk test and expressed as mean \pm standard deviation (SD) (normally distributed variables) or median and interquartile range (variables without normal distribution). Association between categorical variables was assessed by Fisher's exact test or the chi-square test of independence. Between-group comparisons of numerical variables were performed by the Student's t-test or the Wilcoxon MannWhitney test, according to the normality of data distribution. The analysis was performed using the R software, version 3.3.2 and a $5 \%$ significance level was used.

Mean differences of AS between PG and CG were estimated, and the sample size was calculated to test the difference between two means. For calculation of the sample size, we assumed that the variance of the AS measurements in PG and CG would be the same. In addition, we used a ratio of three controls to one psoriatic patient, due to the difficulty in identifying patients with moderate or severe psoriasis (PASI $\geq 7$ ), not using corticosteroids, considering a significance level of $\alpha=5 \%$ and power $(1-\beta)$ of $80 \%$.

\section{Results}

The study sample was composed of 44 subjects, 11 of the PG and 33 of the CG. Mean age was $60.5 \pm 11.3$ years and $59.1 \%$ was white. Mean values of BSA, BMI and WHR were $1.93 \pm 0.20 \mathrm{~m}^{2}, 28.1 \pm 5.2 \mathrm{~kg} / \mathrm{m}^{2}$ and $0.96 \pm 0.06$, respectively. Age was not different between the groups (Table 1).

Regarding lifestyle and comorbidities, $29.5 \%$ of participants consumed alcohol, $29.5 \%$ were smokers, $40.9 \%$ had systemic arterial hypertension, $20.5 \%$ had diabetes and $29.5 \%$ dyslipidemia, with no difference between the groups. With respect to laboratory tests, PG showed higher levels of TC, LDL cholesterol, and C-reactive protein $(p<0.01)$ (Table 1$)$.

The most common medication in the study group was angiotensin II receptor blockers (29.5\%), statins (22.7\%) and diuretics $(18.2 \%)$, with no difference between the groups (data not shown). For the psoriasis treatment, two patients (18\%) of the PG used methotrexate. Only one patient of the PG (9\%) used topical corticosteroids regularly for the skin lesions during the study period.

PG patients showed increased PWV $(9.1 \pm 1.8$ and $8 \pm 2 \mathrm{~m} / \mathrm{s}, \mathrm{p}=0.033$ ), increased IMT of the left common carotid artery $(p=0.018)$ and higher percentage of patients above the $75^{\text {th }}$ percentile according to the ELSA table (54.5 and $18.2 \%, p=0,045)$ when compared with the CG.

Compared with the CG, the PG also showed increased peripheral SBP $(137.1 \pm 13.2$ vs. $122.3 \pm 11.6 \mathrm{mmHg}$, $\mathrm{p}=0.004)$, central SBP $(127 \pm 13$ vs. $112.5 \pm 10.4 \mathrm{mmHg}$, $\mathrm{p}=0.005)$, peripheral DBP $(89.9 \pm 8.9 \mathrm{vs} .82 .2 \pm 8 \mathrm{mmHg}$, $\mathrm{p}=0.022)$, central DBP (91 \pm 9.3 vs. $82.2 \pm 8.3 \mathrm{mmHg}$, $\mathrm{p}=0.014)$, total cholesterol $(252 \pm 43.5 \mathrm{vs} .198 \pm 39.8 \mathrm{mg} / \mathrm{dL}$, $\mathrm{p}<0.001)$, LDL cholesterol $(167 \pm 24 \mathrm{vs.} 118 \pm 40.8 \mathrm{mg} / \mathrm{dL}$, $\mathrm{p}<0.001)$ and $\mathrm{C}$-reactive protein $(7.6 \pm 35.4 \mathrm{vs}$. $1 \pm 1.2 \mathrm{mg} / \mathrm{L}, \mathrm{p}<0,001)$.

There was no difference in Alx@75 between the groups (Table 2).

\section{Discussion}

Psoriasis has been considered an autoimmune, inflammatory disease with important consequences in other systems..$^{5,6,8}$ There are evidences of higher incidence of obesity, diabetes mellitus, arterial hypertension and CVDs - such as acute myocardial infarction and stroke among psoriatic patients. ${ }^{30,31}$ Thus, skin manifestations seem to be just one of the factors associated with this complex condition. It has been speculated that the high amounts of blood inflammatory mediators in psoriatics, in addition to C-reactive protein, such as TNFa and IL-6 may be associated with the inflammatory response to vascular remodeling and cardiovascular changes. ${ }^{31,32}$

In the present study, we included psoriasis patients with $\mathrm{PASI}>7$, i.e., with moderate and severe psoriasis. High C-reactive protein levels found in PG compared with the CG suggests increased inflammatory response, which was associated with higher blood pressure and LDL-cholesterol levels, may contribute to arterial remodeling, as well as to structural and hemodynamic changes observed in these patients. ${ }^{710}$ Coban et al. ${ }^{33}$ showed that systemic inflammation in psoriasis leads to insulin resistance, which, in turn, causes changes in the synthesis of adipokines, including visfatin, vaspin, omentin and adiponectin, which can increase blood pressure, and LDL-cholesterol and TC levels. ${ }^{33}$ In the pathogenesis of atherosclerosis, factors like an altered lipid metabolism, and inappropriate immune response are involved, resulting in arterial wall inflammation. The increased levels of circulating inflammatory mediators contribute to vascular inflammatory response associated with migration of monocytes and oxidation of LDL-cholesterol, which are key elements in the formation of atherosclerotic plaque. ${ }^{31,32}$ However, there are also reports describing the so-called "lipid paradox" in inflammatory diseases, mainly rheumatoid arthritis, marked by a significant decrease in LDL-cholesterol and TC levels 3-5 years before the onset of signs of the disease. ${ }^{34,35}$ There also evidences of possible influence of pharmacological interventions on lipid profile of these patients. ${ }^{36}$

In our study, despite considerable impairment observed in psoriatic patients, this group showed significant increase in atherogenic lipoprotein levels compared with the CG. Only two (18\%) patients used systemic medication, particularly methotrexate. None of the patients used biological drugs. The use of systemic corticosteroids was an exclusion criterion to avoid a bias in the findings.

A systematic review evaluated the metabolic effects of methotrexate in patients with rheumatoid arthritis; ${ }^{37}$ while one study reported differences in lipid profile after one year of treatment, another study reported improvement in lipid concentrations, and their correlation with changes in C-reactive protein levels and blood sedimentation rate, and another study did not find any change in the levels of 


\section{Original Article}

Table 1 - Anthropometric and lifestyle data, comorbidities, and laboratory test results of patients with psoriasis $(n=11)$ and control subjects ( $n=33$ )

\begin{tabular}{|c|c|c|c|}
\hline Variables & Control group $(n=33)$ & Psoriatic group $(n=11)$ & p-value \\
\hline Age (years) & $60 \pm 9$ & $64 \pm 12.5$ & $0.391^{*}$ \\
\hline Ethnicity & & & $0.479^{\dagger}$ \\
\hline White & $21(63.6 \%)$ & $5(45.5 \%)$ & \\
\hline Pardo (multiracial)/Black & $12(36.4 \%)$ & $6(54.5 \%)$ & \\
\hline $\operatorname{BSA}\left(m^{2}\right)$ & $1.92 \pm 0.20$ & $1.94 \pm 0.23$ & $0.835^{\ddagger}$ \\
\hline Weight (kg) & $79.8 \pm 15.1$ & $84.7 \pm 21.6$ & $0.494^{\ddagger}$ \\
\hline $\mathrm{BMI}\left(\mathrm{kg} / \mathrm{m}^{2}\right)$ & $27.2 \pm 4.7$ & $30.9 \pm 5.9$ & $0.079^{\ddagger}$ \\
\hline Waist-hip ratio & $0.96 \pm 0.06$ & $0.97 \pm 0.05$ & $0.576^{\ddagger}$ \\
\hline \multicolumn{4}{|l|}{ Habits } \\
\hline Smoking & $7(21.2 \%)$ & $6(54.5 \%)$ & $0.086^{\dagger}$ \\
\hline Alcohol consumption & $10(30.3 \%)$ & $3(27.3 \%)$ & $1.000^{\S}$ \\
\hline \multicolumn{4}{|l|}{ Comorbidities } \\
\hline Hypertension & $11(33.3 \%)$ & $7(63.6 \%)$ & $0.093^{\S}$ \\
\hline Dyslipidemia & $10(30.3 \%)$ & $3(27.3 \%)$ & $1.000^{\S}$ \\
\hline Diabetes mellitus & $6(18.2 \%)$ & $3(27.3 \%)$ & 0.6698 \\
\hline \multicolumn{4}{|l|}{ Laboratory tests } \\
\hline Total Cholesterol (mg/dL) & $198 \pm 39.8$ & $252 \pm 43.5$ & $<0.001^{*}$ \\
\hline HDL Cholesterol (mg/dL) & $46 \pm 13.5$ & $38 \pm 16.5$ & $0.283^{*}$ \\
\hline LDL Cholesterol (mg/dL) & $118 \pm 40.8$ & $167 \pm 24$ & $<0.001^{*}$ \\
\hline C-reactive protein (mg/L) & $1 \pm 1.2$ & $7.6 \pm 35.4$ & $<0.001^{*}$ \\
\hline
\end{tabular}

${ }^{*}$ Wilcoxon Mann-Whitney test for independent samples (mean $\pm S D$ ), ${ }^{t}$ chi-square test of independence; ₹Student's $t$-test for independent samples (mean $\pm S D$ ),

sFisher's exact test; BMI: body mass index; BSA: body surface area.

lipoproteins, even with reduced C-reactive protein levels. Thus, in light of the conflicting results of these studies and the low percentage of patients using methotrexate, we infer that the possible influence of medications is not relevant on our result. ${ }^{37}$

Among the hemodynamic changes in the PG, the increase in AS, illustrated by an increased PWV, indicates an early vascular aging. ${ }^{38}$ Our results are in accordance with previous studies that reported an increase in PWV in psoriasis patients. ${ }^{39-45}$ Increased PWV has been considered an important predictive factor for cardiovascular outcomes and higher mortality. ${ }^{38}$

Carotid atherosclerosis can be assessed by the IMT measurement and presence of plaques. In our study, we also used imaging test, which confirmed the increased left IMT in the PG. This is in agreement with other studies that showed similar results regardless of other risk factors. ${ }^{43,44}$ Comparison of our results with reference values obtained in the ELSA, we showed a higher percentage of patients above the $75^{\text {th }}$ percentile in the PG. However, this was not true when the results were compared with the MESA. This finding highlights the need for the use of reference tables developed in specific populations.

Regarding the presence of plaques, the apparently higher incidence of plaques in PG compared with the CG was not statistically significant, probably due to the sample size. Also, although a higher incidence of diastolic dysfunction in patients with psoriasis was found in the study by Shang et al., ${ }^{45}$ we did not find significant differences in echocardiographic parameters between the groups. The increased peripheral and central SBP and DBP values found in the PG may be related to the vascular changes observed in these patients, which has also been described in other studies. ${ }^{46,47}$ Although the small number of patients in the PG is a limitations of the study, because of the difficulty in detecting patients who met the inclusion criteria including a PASI $>7$, we were able to show a close relationship between psoriasis and the factors associated with higher probability to develop cardiovascular outcomes. Such associations, found in moderate-to-severe psoriasis patients, are significantly greater than those reported in the general population. More comprehensive studies, including larger sample sizes are suggested, to demonstrate the importance of other predictive factors of CVDs, including an increased Alx@75 and the IMT of the right carotid artery, which did not show statistical difference in our study.

Current guidelines recognize the increased risk for CVDs in patients with psoriasis and the need for its early identification and better stratification. ${ }^{48}$ However, predictive algorithms of cardiovascular risk, such as the Framingham risk score, do not consider the systemic inflammatory effect secondary to psoriasis. ${ }^{9,49}$ Functional parameters, such as the measurement of the AS, as well as structural parameters, such as the use of cardiac and vascular imaging tests, and laboratory biomarkers could be used to improve the sensitivity of traditional algorithms of risk stratification in patients with psoriasis. 
Table 2 - Ultrasound and oscillometry parameters of the brachial artery

\begin{tabular}{|c|c|c|c|}
\hline Parameters & Control group $(n=33$ ) & Psoriatic group $(n=11)$ & $\mathrm{p}$-value \\
\hline IVRT (ms) & $94 \pm 15$ & $104 \pm 12$ & $0.106^{*}$ \\
\hline $\mathrm{DT}(\mathrm{ms})$ & $180 \pm 43$ & $190 \pm 36.5$ & $0.322^{*}$ \\
\hline E/A ratio & $0.86 \pm 0.47$ & $0.88 \pm 0.18$ & $0.456^{*}$ \\
\hline Lateral E/e' ratio & $5.96 \pm 1.42$ & $5.90 \pm 2.28$ & $0.937^{\ddagger}$ \\
\hline Septal E/e' ratio & $6.92 \pm 1.82$ & $7.17 \pm 3.14$ & $0.616^{*}$ \\
\hline LA volume $\left(\mathrm{mL} / \mathrm{m}^{2}\right)$ & $18.41 \pm 4.55$ & $17.50 \pm 5.48$ & $0.626^{\ddagger}$ \\
\hline LVESV (mL) & $34 \pm 9$ & $38 \pm 8$ & $0.086^{*}$ \\
\hline LVEDV (mL) & $106 \pm 26$ & $113 \pm 17$ & $0.606^{*}$ \\
\hline LVEF (\%) & $68 \pm 3$ & $68 \pm 3$ & $0.763^{*}$ \\
\hline Right IMT (mm) & $0.60 \pm 0.12$ & $0.62 \pm 0.16$ & $0.481^{*}$ \\
\hline Left IMT (mm) & $0.61 \pm 0.14$ & $0.72 \pm 0.21$ & $0.018^{*}$ \\
\hline MEDA $>75^{\text {th }}$ percentile & $6(18.2 \%)$ & $3(27.3 \%)$ & $0.669 \S$ \\
\hline ELSA $>75^{\text {th }}$ percentile & $6(18.2 \%)$ & $6(54.5 \%)$ & $0.045^{\S}$ \\
\hline Plaques & $9(27.3 \%)$ & $5(45.5 \%)$ & $0.287^{\S}$ \\
\hline Peripheral SBP (mmHg) & $122.3 \pm 11.6$ & $137.1 \pm 13.2$ & $0.004^{\ddagger}$ \\
\hline Peripheral DBP (mmHg) & $82.2 \pm 8$ & $89.9 \pm 8.9$ & $0.022^{\ddagger}$ \\
\hline $\mathrm{MBP}(\mathrm{mmHg})$ & $99.2 \pm 11.5$ & $108.3 \pm 16$ & $0.105^{\ddagger}$ \\
\hline $\mathrm{PP}(\mathrm{mmHg})$ & $39.8 \pm 6$ & $47.3 \pm 11.4$ & $0.058^{\ddagger}$ \\
\hline Heart rate (bpm) & $70 \pm 14$ & $72 \pm 11$ & $0.989^{*}$ \\
\hline Central SBP (mmHg) & $112.5 \pm 10.4$ & $127 \pm 13$ & $0.005^{\ddagger}$ \\
\hline Central DBP (mmHg) & $82.2 \pm 8.3$ & $91 \pm 9.3$ & $0.014^{\ddagger}$ \\
\hline Central PP (mmHg) & $29.3 \pm 7$ & $36 \pm 8.8$ & $0.020^{*}$ \\
\hline Alx @75(1/min/m²) & $17.64 \pm 10.84$ & $19.15 \pm 10$ & $0.675^{\ddagger}$ \\
\hline PWV (m/s) & $8 \pm 2$ & $9.1 \pm 1.8$ & $0.033^{*}$ \\
\hline
\end{tabular}

*Wilcoxon Mann-Whitney test (mean $\pm S D$ ), ${ }_{t+-S t u d e n t}$ (mean $\pm S D$ ) for independent samples and $\$$ Fisher's exact. IVRT: isovolumic relaxation time; DT: deceleration time; E/A ratio: ratio of the E-wave and A-wave of the left ventricular diastolic filling, LA: left atrial; LVESV: left ventricular end-systolic volume; LVEDV: left ventricular end-diastolic volume; LVEF: left ventricular ejection fraction; IMT: intima-media thickness; MESA: Multi-Ethnic Study of Atherosclerosis; ELSA: Brazilian Longitudinal Study of Adult Health; SBP: systolic blood pressure; DBP: diastolic blood pressure; MBP: mean blood pressure; PP: pulse pressure. Alx @75: Augmentation Index adjusted for a heart rate of 75 beats per minute; PWV: pulse wave velocity.

\section{Conclusion}

Our study shows that psoriatic patients have elevations in carotid IMT and PWV, in addition to increased central and peripheral blood pressure, and serum cholesterol and C-reactive protein levels.

\section{Limitations}

One possible limitation of this study is the small sample size, due to the difficulty in recruiting patients with moderate and severe psoriasis (PASI $>7$ ), not using corticosteroids, which could affect the outcome measures. Another possible limitation is the recruitment of patients from one location only.

\section{Author contributions}

Conception and design of the research and Analysis and interpretation of the data: Oliveira AN, Simões MM, Simões R, Rezende BA, Malachias MVB; Acquisition of data: Oliveira AN, Simões MM, Rezende BA, Malachias MVB; Writing of the manuscript and Critical revision of the manuscript for intellectual content: Oliveira AN, Rezende BA, Malachias MVB.

\section{Potential Conflict of Interest}

No potential conflict of interest relevant to this article was reported.

\section{Sources of Funding}

There were no external funding sources for this study.

\section{Study Association}

This article is part of the thesis of master submitted by Angélica Navarro de Oliveira, from Faculdade de Ciências Medicas de Minas Gerais.

\section{Ethics approval and consent to participate}

This study was approved by the Ethics Committee of the Faculdade de Ciências Médicas de Minas Gerais under the protocol number 1.267.197. All the procedures in this study were in accordance with the 1975 Helsinki Declaration, updated in 2013. Informed consent was obtained from all participants included in the study. 


\section{References}

1. Raychaudhuri SP, Farber EM. The prevalence of psoriasis in the world. J Eur Acad Dermatol Venereol. 2001;15(1):16-7.

2. Kim WB, Jerome D, Yeung J. Diagnosis and management of psoriasis. Can Fam Physician. 2017;63(4):278-85.

3. Ayala-Fontánez N, Soler DC, McCormick TS. Current knowledge on psoriasis and autoimmune diseases. Psoriasis (Auckl). 2016 Feb;6:7-32.

4. Duarte GV, Porto-Silva L, de Oliveira MF. Epidemiology and treatment of psoriasis: a Brazilian perspective. Psoriasis (Auckl). 2015 Apr;5:55-64.

5. Griffiths CE, Barker JN. Pathogenesis and clinical features of psoriasis. Lancet. 2007;370(9583):263-71.

6. Miller IM, Ellervik C, Yazdanyar S, Jemec GB. Meta-analysis of psoriasis, cardiovascular disease, and associated risk factors. J Am Acad Dermatol. 2013;69(6):1014-24

7. Miller IM, Skaaby T, Ellervik C, Jemec GB. Quantifying cardiovascular disease risk factors in patients with psoriasis: a meta-analysis. Br J Dermatol. $2013 ; 169(6): 1180-7$

8. Ogdie A, Schwartzman S, Eder L, Maharaj AB, Zisman D, Raychaudhuri SP, et al. Comprehensive treatment of psoriatic arthritis: managing comorbidities and extraarticular manifestations. J Rheumatol. 2014;41(11):2315-22.

9. Mehta NN, Azfar RS, Shin DB, Neimann AL, Troxel AB, Gelfand JM. Patients with severe psoriasis are at increased risk of cardiovascular mortality: cohort study using the General Practice Research Database. Eur Heart J. 2010;31(8):1000-6.

10. Vlachopoulos C, Xaplanteris P, Aboyans V, Brodmann M, Cífková R, Cosentino $F$, et al. The role of vascular biomarkers for primary and secondary prevention. A position paper from the European Society of Cardiology Working Group on peripheral circulation: Endorsed by the Association for Research into Arterial Structure and Physiology (ARTERY) Society. Atherosclerosis. 2015;241(2):507-32.

11. Takimura CK, Lemos PA, Perin MA, da Silva EE, Ambrose J, Ramires JA, et al. Angiographic geometric predictors of myocardial infarction are not associated with ultrasonographic markers of plaque vulnerability. Arq Bras Cardiol. 2006;87(2):99-105.

12. Malachias MV, Ferreira S, Souza WK, Ribeiro JM, Miranda RD, Jardim TS. 7th Brazilian Guideline of Arterial Hypertension: Chapter 11 - Arterial Hypertension in the elderly. Arq Bras Cardiol. 2016;107(3 Suppl 3):64-6.

13. Obesity: preventing and managing the global epidemic. Report of a WHO consultation. World Health Organ Tech Rep Ser. 2000;894:i-xii, 1-253.

14. Faludi AA, Izar MC, Saraiva JF, Chacra AP, Bianco HT, Afiune A, et al. Atualização da Diretriz Brasileira de Dislipidemias e Prevenção da Aterosclerose - 2017. Arq Bras Cardiol. 2017;109(2 Suppl 1):1-76.

15. Biomarkers Definitions Working Group. Biomarkers and surrogate endpoints: preferred definitions and conceptual framework. Clin Pharmacol Ther. 2001;69(3):89-95.

16. Schmitt J, Wozel G. The psoriasis area and severity index is the adequate criterion to define severity in chronic plaque-type psoriasis. Dermatology. $2005 ; 210(3): 194-9$.

17. Siqueira AL, Sakurai E, Souza MCFM. Dimensionamento de amostragem em estudos clínicos e epidemiológicos. 1 ed. Salvador: Associação Brasileira de Estatística (ABE), 2001. p.126.

18. Rondina RD, Gorayeb R, Botelho C, Silva AM. A Relação entre Tabagismo e Características Socio-Demográficas em Universitários. Psic, Saúde \& Doenças. 2005 Jul;6:35-45.

19. World Health Organization. (WHO). Global status report: alcohol policy. Geneva; 2004.

20. American Diabetes Association. 2. Classification and Diagnosis of Diabetes. Diabetes Care. 2018;41(Suppl 1):S13-27.
21. Fredriksson T, Pettersson U. Severe psoriasis--oral therapy with a new retinoid. Dermatologica. 1978;157(4):238-44.

22. Hametner B, Wassertheurer S, Kropf J, Mayer C, Eber B, Weber T. Oscillometric estimation of aortic pulse wave velocity: comparison with intra-aortic catheter measurements. Blood Press Monit. 2013;18(3):173-6.

23. Weber T, Wassertheurer S, Rammer M, Maurer E, Hametner B, Mayer CC, et al. Validation of a brachial cuff-based method for estimating central systolic blood pressure. Hypertension. 2011;58(5):825-32.

24. Nunan D, Wassertheurer S, Lasserson D, Hametner B, Fleming S, Ward A, et al. Assessment of central haemomodynamics from a brachial cuff in a community setting. BMC Cardiovasc Disord. 2012;12:48.

25. Freire CM, Alcantara ML, Santos SN, Veloso O, Porto CLL, Barros MV et al. Recomendação para a Quantificação pelo Ultrassom da Doença Aterosclerótica das Artérias Carótidas e Vertebrais: Grupo de Trabalho do Departamento de Imagem Cardiovascular da Sociedade Brasileira de Cardiologia - DIC - SBC. Arq Bras Cardiol: Imagem cardiovasc. 2015 Abril; 28:e1- 64

26. Aquino EM, Barreto SM, Bensenor IM, Carvalho MS, Chor D, Duncan BB, et al. Brazilian Longitudinal Study of Adult Health (ELSA-Brasil): objectives and design. Am J Epidemiol. 2012;175(4):315-24.

27. Polak JF, Pencina MJ, O'Leary DH, D'Agostino RB. Common carotid artery intima-media thickness progression as a predictor of stroke in multi-ethnic study of atherosclerosis. Stroke. 2011;42(11):3017-21.

28. Lang RM, Badano LP, Mor-Avi V, Afilalo J, Armstrong A, Ernande L, et al. Recommendations for cardiac chamber quantification by echocardiography in adults: an update from the American Society of Echocardiography and the European Association of Cardiovascular Imaging. J Am Soc Echocardiogr. 2015;28(1):1-39.e14.

29. Nagueh SF, Smiseth OA, Appleton CP, Byrd BF, Dokainish H, Edvardsen $\mathrm{T}$, et al. Recommendations for the Evaluation of Left Ventricular Diastolic Function by Echocardiography: An Update from the American Society of Echocardiography and the European Association of Cardiovascular Imaging. Eur Heart J Cardiovasc Imaging. 2016;17(12):1321-60.

30. Brauchli YB, Jick SS, Miret M, Meier CR. Psoriasis and risk of incident myocardial infarction, stroke or transient ischaemic attack: an inception cohort study with a nested case-control analysis. Br J Dermatol. 2009;160(5):1048-56.

31. Weber $\mathrm{C}$, Noels $\mathrm{H}$. Atherosclerosis: current pathogenesis and therapeutic options. Nat Med. 2011;17(11):1410-22.

32. Ketelhuth DF, Hansson GK. Modulation of autoimmunity and atherosclerosis - common targets and promising translational approaches against disease. Circ J. 2015;79(5):924-33.

33. Coban M, Tasli L, Turgut S, Özkan S, Tunç Ata M, Akın F. Association of Adipokines, Insulin Resistance, Hypertension and Dyslipidemia in Patients with Psoriasis Vulgaris. Ann Dermatol. 2016;28(1):74-9.

34. Myasoedova E, Crowson CS, Kremers HM, Fitz-Gibbon PD, Therneau TM, Gabriel SE. Total cholesterol and LDL levels decrease before rheumatoid arthritis. Ann Rheum Dis. 2010;69(7):1310-4.

35. Soeiro AM, Haddad M, de Almeida MC, Ruppert AD, Serrano CV. Rheumatoid arthritis and cardiovascular disease: what is known about this relationship and what can currently be done for affected patients? Rev Port Cardiol. 2012;31(3):225-32.

36. Urruela MA, Suarez-Almazor ME. Lipid paradox in rheumatoid arthritis: changes with rheumatoid arthritis therapies. Curr Rheumatol Rep. 2012;14(5):428-37.

37. Westlake SL, Colebatch AN, Baird J, Kiely P, Quinn M, Choy E, et al. The effect of methotrexate on cardiovascular disease in patients with rheumatoid arthritis: a systematic literature review. Rheumatology (Oxford). 2010;49(2):295-307. 
38. Mikael LR, Paiva AM, Gomes MM, Sousa ALL, Jardim PC, Vitorino PV, et al. Vascular Aging and Arterial Stiffness. Arq Bras Cardiol. 2017;109(3):253-8.

39. Neimann AL, Shin DB, Wang X, Margolis DJ, Troxel AB, Gelfand JM. Prevalence of cardiovascular risk factors in patients with psoriasis. J Am Acad Dermatol. 2006;55(5):829-35.

40. Anandarajah AP, Ritchlin CT. Pathogenesis of psoriatic arthritis. Curr Opin Rheumatol. 2004;16(4):338-43.

41. Costa L, Caso F, D'Elia L, Atteno M, Peluso R, Del Puente A, et al. Psoriatic arthritis is associated with increased arterial stiffness in the absence of known cardiovascular risk factors: a case control study. Clin Rheumatol. 2012;31(4):711-5

42. Balta I, Balta S, Demirkol S, Celik T, Ekiz O, Cakar M, et al. Aortic arterial stiffness is a moderate predictor of cardiovascular disease in patients with psoriasis vulgaris. Angiology. 2014;65(1):74-8.

43. Eder L, Gladman DD. Atherosclerosis in psoriatic disease: latest evidence and clinical implications. Ther Adv Musculoskelet Dis. 2015;7(5):187-95.

44. Tyrrell PN, Beyene J, Feldman BM, McCrindle BW, Silverman ED, Bradley TJ. Rheumatic disease and carotid intima-media thickness: a systematic review and meta-analysis. Arterioscler Thromb Vasc Biol. 2010;30(5):1014-26

45. Shang Q, Tam LS, Yip GW, Sanderson JE, Zhang Q, Li EK, et al. High prevalence of subclinical left ventricular dysfunction in patients with psoriatic arthritis. J Rheumatol. 2011;38(7):1363-70

46. Takeshita J, Wang S, Shin DB, Mehta NN, Kimmel SE, Margolis DJ, et al. Effect of psoriasis severity on hypertension control: a population-based study in the United Kingdom. JAMA Dermatol. 2015;151(2):161-9.

47. Yeung H, Takeshita J, Mehta NN, Kimmel SE, Ogdie A, Margolis DJ, et al. Psoriasis severity and the prevalence of major medical comorbidity: a population-based study. JAMA Dermatol. 2013;149(10):1173-9.

48. Roubille C, Richer V, Starnino T, McCourt C, McFarlane A, Fleming P, et al Evidence-based Recommendations for the Management of Comorbidities in Rheumatoid Arthritis, Psoriasis, and Psoriatic Arthritis: Expert Opinion of the Canadian Dermatology-Rheumatology Comorbidity Initiative. J Rheumatol. 2015;42(10):1767-80.

49. Eder L, Chandran V, Gladman DD. The Framingham Risk Score underestimates the extent of subclinical atherosclerosis in patients with psoriatic disease. Ann Rheum Dis. 2014;73(11):1990-6. 
